\title{
Simulations of Learning, Memory, and Forgetting Processes with Model of CA1 Region of the Hippocampus
}

\author{
Dariusz Świetlik (DD \\ Intrafaculty College of Medical Informatics and Biostatistics, Medical University of Gdańsk, 1 Debinki St., 80-211 Gdańsk, Poland \\ Correspondence should be addressed to Dariusz Świetlik; dswietlik@gumed.edu.pl
}

Received 4 April 2018; Revised 30 July 2018; Accepted 28 October 2018; Published 10 December 2018

Guest Editor: Ireneusz Czarnowski

Copyright (C) 2018 Dariusz Świetlik. This is an open access article distributed under the Creative Commons Attribution License, which permits unrestricted use, distribution, and reproduction in any medium, provided the original work is properly cited.

The aim of this paper is to present a computational model of the CA1 region of the hippocampus, whose properties include (a) attenuation of receptors for external stimuli, (b) delay and decay of postsynaptic potentials, (c) modification of internal weights due to propagation of postsynaptic potentials through the dendrite, and (d) modification of weights for the analog memory of each input due to a pattern of long-term synaptic potentiation (LTP) with regard to its decay. The computer simulations showed that CA1 model performs efficient LTP induction and high rate of sub-millisecond coincidence detection. We also discuss a possibility of hardware implementation of pyramidal cells of CA1 region of the hippocampus.

\section{Introduction}

Hippocampus is a neural structure located in brain in medial temporal lobe, under the cerebral cortex. Being a part of limbic system, hippocampus plays main role in cortical memory [1-4] navigation [5-10] and conditioning [11-13]. In basic hippocampal circuit, a series of narrow zones could be distinguished, part of which are Cornu Ammonis (CA) areas filled with pyramidal cells. CA1 and CA3 are proven to be areas of highest significance [14-17].

Most of reviewed models are associated with memory and imply that hippocampus is working as a homogenous network [18]. These models do not assume any differentiation among CA1 and CA3. Among numerous hippocampal models only a few specify a role for CA1; however there are many examples of synaptic integration among pyramidal cells in CAl area presenting no connection with their basic function.

Scientific research was primarily concentrated on the potential of CA3 areas, mostly the ability of cells to autoassociate $[19,20]$ or to associate activity in sequences [21, 22]. Treves and Rolls [19] suggested that CA3 requires recording into a stronger code and takes benefits from this process. Otherwise, McClelland and Goddard [20] presented slightly different point of view, in which CA3 are too strong for direct association. As a result, the invertible code might cause confusion among superficial and deep layers of entorhinal cortex.

Following Marr's inspiration [23], Treves and Rolls improved a precise and successful hippocampus memory model, in which CA3 is area associated with recurrent collaterals and memory recall $[19,24-27]$. In this model possible functions of CA1 are also mentioned. It is suggested that CA1 are responsible for insurance of effective information transmission and reduction of CA3 excessive activity [28-31].

However, O'Reilly and McClelland [32] presented a slightly different expertise in which CA1 areas are required to solve the problem of associating CA3 activity with the primal entorhinal activity. McClelland and Goddard [20] developed a model, in which CA1 cells contact EC cells and have direct connections to them. Another point of view suggesting connection between CA3 cells and dentate gyrus is given by Lisman [33]. Nevertheless, Lisman and Otmakhova [22] declared that storage of new information in hippocampus requires activation of dopamine receptor which enables temporoammonic input activity. Dopamine has ability to inhibit reaction caused by temporoammonic stimulation and simplify the induction of early LTP in the Schaffer collateral [34] without interfering in their response [35].

Implementation of CA1 presented in model given by Hasselmo and Schnell [36] imputes a crucial role to acetylcholine, 
which is presented as the main agent performing suppression [37]. Otherwise, Hasselmo et al. submit implication for CA1 in which the theta rhythm pertains separate phases of storage and recall in CA1 and CA3 [38].

Another model, presented by Levy, concentrates on more general or predicted function of CA1 and might not be compatible with proven activity of hippocampus [39]. A temporoammonic input activity is suggested to take place in CA1 and is associated with activity in CA3 through the Schaffer collaterals. Furthermore, it could be possible that that temporoammonic input blocks Schaffer collateral vividness in order to determine which active CA1 cells can be connected with active CA3 cells. In this model CA1 are viewed as a decoder of CA3 activity, like subiculum and entorhinal cortex, while CA3 recurrent collaterals simplify the preservation of sequences [40]. The prediction of existing dependent on time plasticity in the Schaffer collaterals is examined and supported by Nishiyama et al. [41].

On the contrary, Lorincz and Buzsaki [18] suggest that the mismatch between the current input and events recalled by hippocampus is calculated in the entorhinal cortex. The contribution to CA1 is observed during activity by using delta rule [42]. Those hypothetical learning rules based on mathematics are given by Lorincz [43]; however in the previous version of this theory there is no precise input to CA1 [44].

The hippocampus is an area in human brain, which becomes activated in order to process temporal orders of events. CA1 involve this region in the memory of objects, odors, and, what is more important, their sequences [45]. Another promising conclusion might be a relation of temporal delays in the neural circuitry of the medial entorhinal cortex to temporal adjustment process, which could result in the various volume of spatial grids found in the medial entorhinal cortex [46]. Various types of neuron cells' firing rates are high at different times, within a trial or delay period [47-49].

The role of hippocampus in contextual learning of objects recognition must be also mentioned [50]. And even simply models of hippocampal circuits could prove new explanations in human pathology such as Alzheimer disease or drugs art of work. It is well established that the connections from entorhinal cortex layer 2 to hippocampus play a crucial role in development of Alzheimer pathology [51]. Cannabinoids disrupt memory encoding by functionally isolating hippocampal CA1 from CA3 [52].

In Section 2, we introduce mathematical model of CA1 region of the hippocampus microcircuit and discuss the methods simulation CA1 (Sections 2.1 and 2.2). Additionally, in Sections 2.3-2.5, we describe mathematical presentations: pyramidal, basket, and O-LM cells of CA1 region, while, in Sections 2.6-2.7, we present CA1 network inputs and synaptic properties glutamate and GABA receptors. In Section 3, we present the results of the paper. In Section 4, we fully discuss our results. Section 5 summarizes the conclusions.

\section{Materials and Methods}

2.1. The Model Description. The CA1 microcircuit is presented of Figure 1. Our simulations of the hippocampus are based on computational models from previous studies
$[53,54]$. There are four pyramidal cells (P1, P2, P3, and P4), two basket (B1, B2), one O-LM cell (inhibitory interneurons), and 3 independently programmed theta rhythm generators. Such sparse network with strictly topographically related connections is very similar to the CA1 net used by Hasselmo and Cutsuridis [55]. And in our opinion it has more biological plausibility as compared to previous Cutsuridis network with 100 pyramidal cells and nearly to all interconnections [56].

We have used the theta oscillation in our previous studies [53, 54], which were based on faster gamma-frequency oscillations [1, 57-60], spatial information [61-63], in-time locking cell activities [64], and regulation of learning facilities [1, 65-67].

The MS-DBB (Medial Septum-Diagonal Band of Broca) has been classically viewed as the hippocampal theta rhythm generator $[57,64,68]$. However, the role of the MS-DBB in hippocampal theta oscillations must be revised in light of recent discovery that the hippocampus itself can generate a theta-frequency rhythm independent of the MS-DBB [69]. Huh et al. suggest that the MS-DBB is one of several extrinsic rhythm generators that amplify and regulate intrinsic theta generators within the hippocampus [70]. Hence, the hippocampal theta rhythm recorded in vivo may be a product of several interacting intrinsic and extrinsic theta generators working in concert. It remains to be elucidated what role glutamatergic, GABAergic, and most importantly cholinergic MS-DBB neurons [71] play in these interactions; the understanding of these matters will bring new insights into the mechanisms underlying functions such as spatial learning and memory. In our model we have employed the most simple theta generators, which depict the basic Wang [68] suggestions, but we have not considered the proposals of Hajos [72], as the reciprocal Septo-Hippocampal connections are much more complicated as in the skeleton network of Hajos [72]. The T1, T2, and T3 theta generators send the series of 8 bursts every second; it means $8 \mathrm{~Hz}$ theta frequency. Each burst consists of 5 spikes at $100 \mathrm{~Hz}$; for T2 and T3 we have a faze delay of 10 and 20 milliseconds for burst activity.

2.2. Art of Work. The mathematical description of equations and parameters that we used in our simulations was based on our previous studies on single neuron model [53] and sparse CA3 network model [54]. All mathematical descriptions of CA1 model neurons are presented in Table 1.

2.3. CA1 Pyramidal Cells. Every CA1 pyramidal cell consists of 16 compartments in which each dendrite has an excitatory or inhibitory synapse. There are glutamate receptors for excitatory inputs: AMPA - E (k, i), NMDA - M (k, i). GABA receptors are for inhibitory inputs: $I(k, i)$ while $k$ is the number of dendrite compartments and $i$ is the number of area register table. There are dendrites constructed within a course of compartments. Each CA1 cell receives somatic synaptic inhibition from CAl basket cells, proximal excitation from CA1 pyramidal cells, mid-dendritic excitation from Mossy Fibers, and distal apical excitation from the layer 3 entorhinal cortex $[73,74]$. 


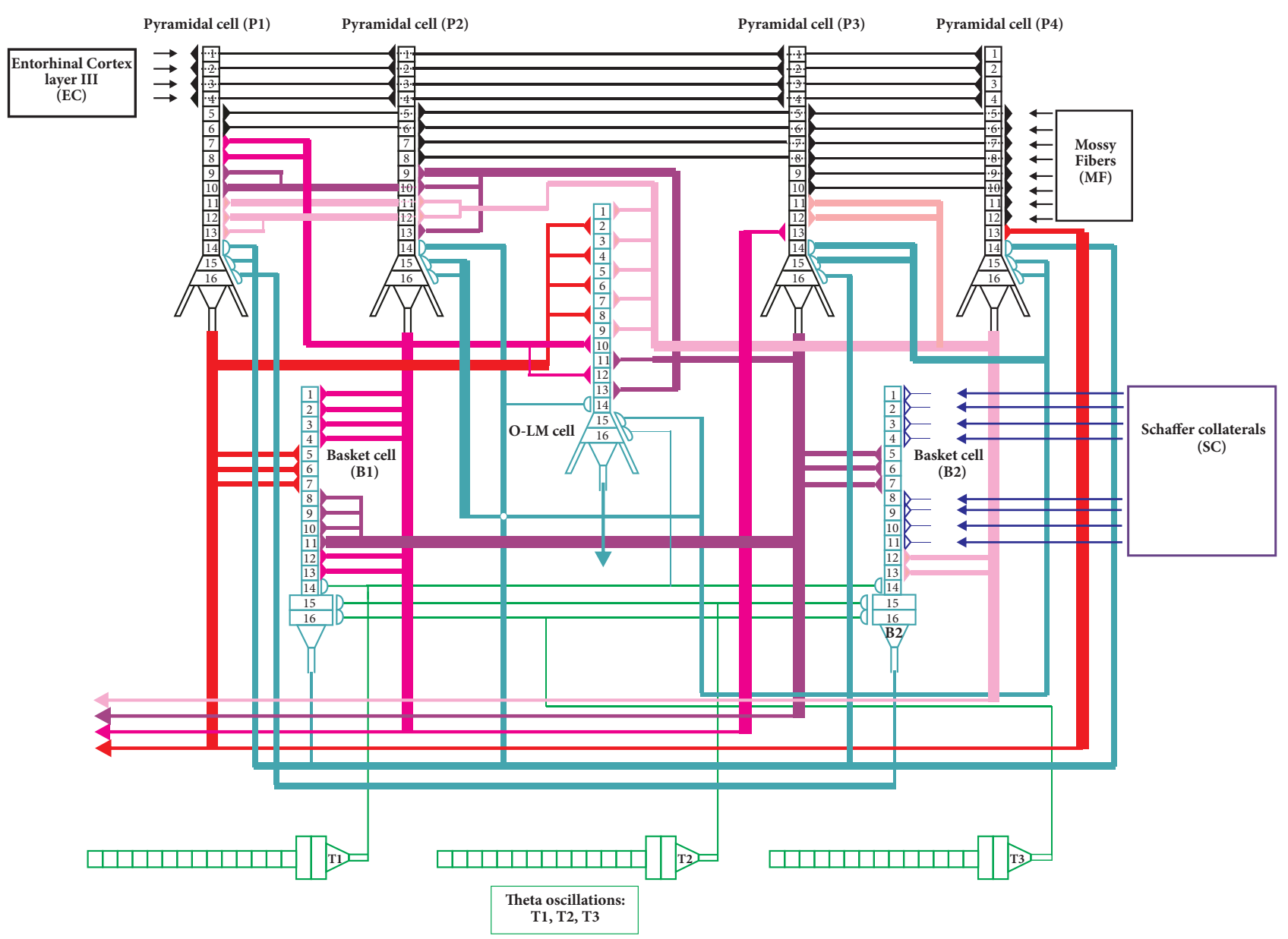

FIGURE 1: Hippocampal formation CA1 microcircuit showing pyramidal, basket, and OL-M cells. CA1 network: P1, P2, P3, P4: pyramidal cells; B1, B2: basket cells; and OL-M cell. Each CA1 pyramidal cell received distal apical excitation from the layer 3 entorhinal cortex (EC) and mid-dendritic excitation from Mossy Fibers (MF).

2.4. CA1 Basket Cells. Every CA1 basket cell consists of 16 compartments in which each dendrite has an excitatory or inhibitory synapse. There are glutamate receptors for excitatory inputs: AMPA - E (k, i), NMDA - M (k, i). GABA receptors are for inhibitory inputs: I $(k, i)$ while $\mathrm{k}$ is the number of dendrite compartments and $\mathrm{i}$ is the number of area register table. There are dendrites constructed within a course of compartments. Each basket cell receives somatic synaptic inhibition from the medial septum (theta oscillations) and neighboring basket cells in their soma. Excitatory connections are received to their distal dendrites form layer 3 entorhinal cortex and to medium dendrites from both CA1 pyramidal cells and CA3 Schaffer collaterals.

2.5. CA1 O-LM Cells. Every CA1 O-LM cell consists of 16 compartments in which each dendrite has an excitatory or inhibitory synapse. There are glutamate receptors for excitatory inputs: AMPA - E (k, i), NMDA - M (k, i). GABA receptors are for inhibitory inputs: $I(k, i)$ while $k$ is the number of dendrite compartments and $\mathrm{i}$ is the number of area register table. There are dendrites constructed within a course of compartments. Each O-LM cell receives excitatory and inhibitory connections. First ones were received from active CA1 cells, whereas second ones were received from the medial septum (theta oscillations: T1, T2, and T3).

2.6. Model Inputs. According to Witter sources of inputs to CA1 are Mossy Fibers and entorhinal cortex layers III [75] as well as disinhibitory theta input from medial septal area. Every CA1 pyramidal cell input from Mossy Fibers was presented as the firing at an average frequency of $44 \mathrm{~Hz}$ and from layer 3 entorhinal cortex of $24 \mathrm{~Hz}$. Each CA1 basket cell input from CA3 Schaffer collaterals was modeled as firing at an average frequency of $50 \mathrm{~Hz}$ and from the medial septum at $8 \mathrm{~Hz}$ theta rhythm. All initial parameters of microcircuit model of CA1 network are presented in Table 2. Pyramidal cells received somatic synaptic inhibition from CA1 basket cells (B1, B2), proximal excitation from CA1 pyramidal cells (P1, P2, P3, and P4), mid-dendritic excitation from Mossy Fibers (MF), and distal apical excitation from the layer III entorhinal cortex (EC). Basket cell received somatic synaptic inhibition from the medial septum (theta oscillations: T1, T2, and T3). Excitatory connections are received from both CA1 pyramidal cells (P1, P2, P3, and P4) and CA3 Schaffer 
TABLE 1: The most important mathematical issues of the model cells of CA1 region.

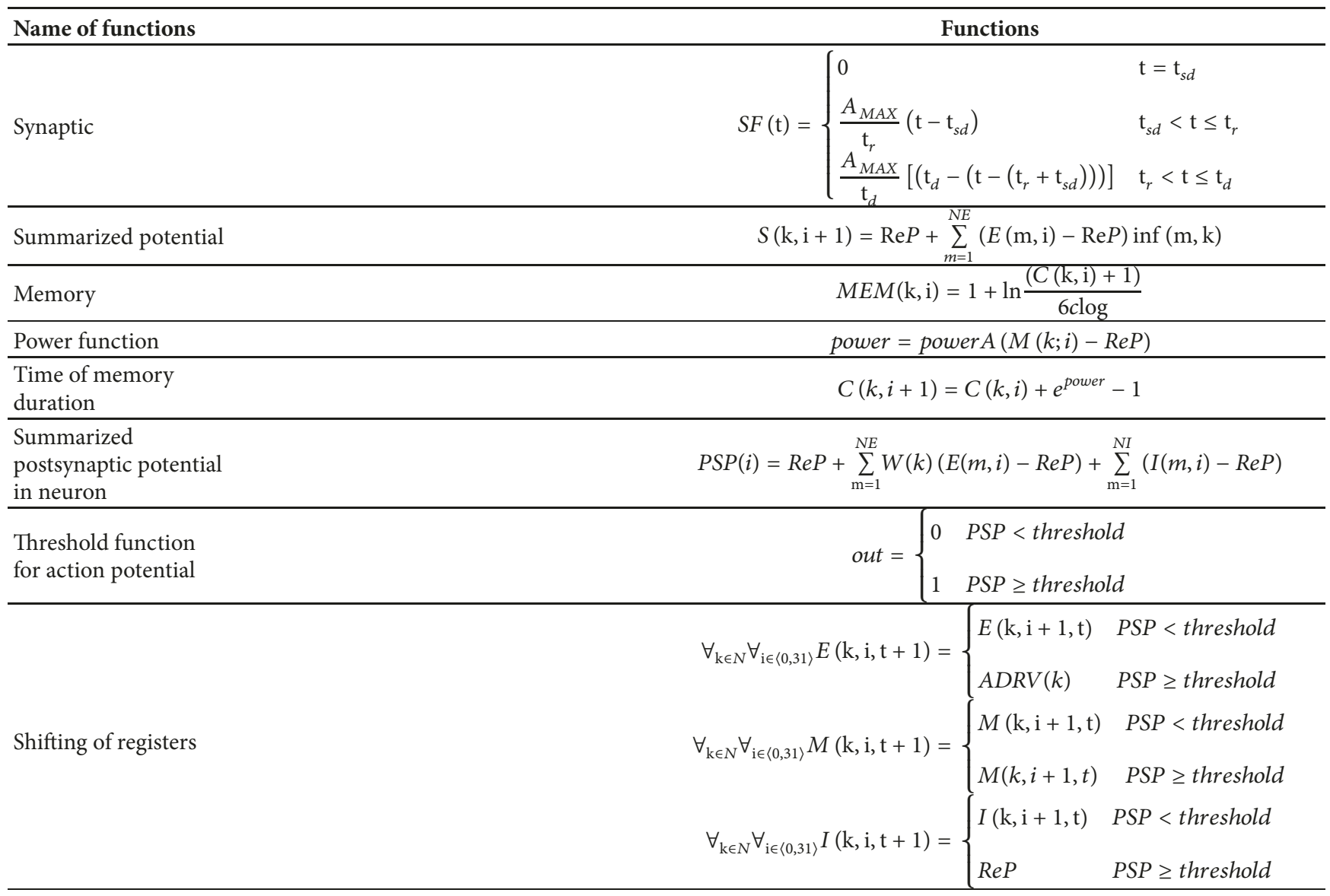

TABLE 2: Initial parameters microcircuit model of CA1 network.

\begin{tabular}{lcccccccccc}
\hline CA1 cells & LTP $($ Memory) & NE & NI & Threshold & ReP & LSW & CaMT & EPSPd & IPSPd & FQ \\
\hline Pyramidal cell (P1) & on & 13 & 3 & -50 & -80 & 0,2 & -68 & 4,5 & -6 & 10 \\
\hline Pyramidal cell (P2) & on & 13 & 3 & -50 & -80 & 0,2 & -68 & 4,5 & -6 & 10 \\
\hline Pyramidal cell (P3) & on & 13 & 3 & -50 & -80 & 0,2 & -68 & 4,5 & -6 & 10 \\
\hline Pyramidal cell (P4) & on & 13 & 3 & -50 & -80 & 0,2 & -68 & 4,5 & -6 & 10 \\
\hline Basket cell (B1) & off & 13 & 3 & -50 & -80 & 1 & -68 & 4 & $-4,5$ & 10 \\
\hline Basket cell (B2) & off & 13 & 3 & -50 & -80 & 1 & -68 & 4 & $-5,5$ & 10 \\
\hline O-LM cell & off & 13 & 3 & -50 & -80 & 0,6 & -68 & 4 & -4 & 10 \\
\hline
\end{tabular}

collaterals (SC). O-LM cells receive excitatory and inhibitory connections. First ones are received from active CA1 cells (P1, $\mathrm{P} 2, \mathrm{P} 3$, and $\mathrm{P} 4)$, whereas second ones are received from the basket cells (B1, B2). Hippocampal formation of CA1 microcircuit connections is presented in Table 3. As compared with the previous model of CA3 microcircuit, we have inputs from layer III of entorhinal cortex instead of those from layer II $(*)$. The Mossy Fibers $(* *)$ subsequently diminish in range; instead we have intermingled input from pyramidal cells with each other through the Schafer collaterals (Table 3).

2.7. Synaptic Properties. The mathematical description of the glutamate receptors AMPA, NMDA, and the GABA receptor was based on our previous studies $[53,54]$. The real value of postsynaptic potential is estimated by using functions from Table 1. During these studies all pyramidal cells had the same LSW parameter $(0,2)$. However during our previous studies on CA3 microcircuit, the pyramidal cells used LSW ranging from 0,6 to $0,7[53,54]$.

\section{Results}

Two simulations were used, one without LTP induction and one with LTP induction. For LTP induction pyramidal cells (P1, P2, P3, and P4) were strongly excited on inputs 7, 8, and 9 by stimulation at $100 \mathrm{~Hz}$ for $400 \mathrm{~ms}$. Such approach was inspired by the well-known phenomenon where during the 
TABLE 3: Connections of hippocampal CA1 microcircuit.

\begin{tabular}{|c|c|c|c|c|c|c|c|c|c|c|c|c|c|c|c|c|}
\hline \multirow{2}{*}{ CA1 cells } & \multicolumn{13}{|c|}{ Inputs } & \multirow[b]{2}{*}{14} & \multirow[b]{2}{*}{15} & \multirow[b]{2}{*}{16} \\
\hline & 1 & 2 & 3 & 4 & 5 & 6 & 7 & 8 & 9 & 10 & 11 & 12 & 13 & & & \\
\hline Pyramidal cell (P1) & $\mathrm{EC}_{3} *$ & $\mathrm{EC}_{3} *$ & $\mathrm{EC}_{3} *$ & $\mathrm{EC}_{3} *$ & $\mathrm{MF} * *$ & $\mathrm{MF} * *$ & $\mathrm{P} 2$ & $\mathrm{P} 2$ & P3 & P3 & $\mathrm{P} 4$ & $\mathrm{P} 4$ & $\mathrm{P} 4$ & $\mathrm{~B} 1$ & $\mathrm{~B} 1$ & B2 \\
\hline Pyramidal cell (P2) & $\mathrm{EC}_{3} *$ & $\mathrm{EC}_{3} *$ & $\mathrm{EC}_{3} *$ & $\mathrm{EC}_{3} *$ & $\mathrm{MF} * *$ & $\mathrm{MF} * *$ & $\mathrm{MF} * *$ & $\mathrm{MF} * *$ & P3 & P3 & $\mathrm{P} 4$ & $\mathrm{P} 4$ & $\mathrm{P} 3$ & $\mathrm{~B} 1$ & $\mathrm{~B} 2$ & $\mathrm{~B} 2$ \\
\hline Pyramidal cell (P3) & $\mathrm{EC}_{3} *$ & $\mathrm{EC}_{3} *$ & $\mathrm{EC}_{3} *$ & $\mathrm{EC}_{3} *$ & $\mathrm{MF} * *$ & $\mathrm{MF} * *$ & $\mathrm{MF} * *$ & $\mathrm{MF} * *$ & $\mathrm{MF} * *$ & $\mathrm{MF} * *$ & $\mathrm{P} 4$ & $\mathrm{P} 4$ & $\mathrm{P} 2$ & $\mathrm{~B} 2$ & $\mathrm{~B} 2$ & $\mathrm{~B} 1$ \\
\hline Pyramidal cell (P4) & $\mathrm{EC}_{3} *$ & $\mathrm{EC}_{3} *$ & $\mathrm{EC}_{3} *$ & $\mathrm{EC}_{3} *$ & $\mathrm{MF} * *$ & $\mathrm{MF} * *$ & $\mathrm{MF} * *$ & $\mathrm{MF} * *$ & $\mathrm{MF} * *$ & $\mathrm{MF} * *$ & $\mathrm{MF} * *$ & $\mathrm{MF} * *$ & $\mathrm{P} 1$ & $\mathrm{~B} 1$ & $\mathrm{~B} 2$ & $\mathrm{~B} 2$ \\
\hline Basket cell (B1) & $\mathrm{P} 2$ & $\mathrm{P} 2$ & $\mathrm{P} 2$ & $\mathrm{P} 2$ & $\mathrm{P} 1$ & $\mathrm{P} 1$ & $\mathrm{P} 1$ & P3 & $\mathrm{P} 3$ & $\mathrm{P} 3$ & $\mathrm{P} 3$ & $\mathrm{P} 2$ & $\mathrm{P} 2$ & $\mathrm{~T} 1$ & $\mathrm{~T} 2$ & $\mathrm{~T} 3$ \\
\hline Basket cell (B2) & SC & SC & SC & SC & $\mathrm{P} 3$ & $\mathrm{P} 3$ & P3 & SC & SC & SC & SC & $\mathrm{P} 4$ & $\mathrm{P} 4$ & $\mathrm{~T} 1$ & $\mathrm{~T} 2$ & $\mathrm{~T} 3$ \\
\hline O-LM cell & $\mathrm{P} 4$ & $\mathrm{P} 1$ & $\mathrm{P} 4$ & $\mathrm{P} 1$ & $\mathrm{P} 4$ & $\mathrm{P} 1$ & $\mathrm{P} 4$ & $\mathrm{P} 1$ & $\mathrm{P} 4$ & $\mathrm{P} 2$ & P3 & $\mathrm{P} 2$ & P3 & $\mathrm{B} 1$ & $\mathrm{~B} 2$ & $\mathrm{~B} 2$ \\
\hline
\end{tabular}

environmental activity the firing rate at particular hippocampal connections increases rapidly [76]. Firing histograms of the 3 cells' groups and theta oscillation including stimulation with and without LTP are given in Figures 2 and 3. Those stimulations refer to Bliss and Lomo research work $[77,78]$.

The stimulated pyramidal cells have a phase preference compatible with the theta rhythm. O-LM cell are able to intrinsically oscillate at the theta rhythm and become extremely active during theta oscillations. However, there is no visible contribution of O-LM cells to the synchronization of pyramidal cells in the CA1 network. Otherwise, in response to septum inhibitory input, basket cells oscillate.

In both simulations, after the training course, there is a significant increase in the values of LTP and frequency of action-potential generation. The CA1 model represents also clearly the heterosynaptic LTP as emerged from online observations of all numerical values during simulations.

Configuration of CA1 network without LTP inducing protocol was also examined and no output increased frequency was observed. What is more, after the 3rd second of simulation an LTP induction was noticeable because of a narrow coincidence of neighboring excitatory inputs after 2 seconds of simulation. The examination carried out without LTP inducing protocol presents the stabilization of pyramidal cells output frequency at the value of $34.5 \mathrm{~Hz}$ (SD 0.827). This value stabilizes after 10 seconds of simulation and is similar to average frequency input (35.22) (Figure 4). There might be a conclusion that LTP induction simplifies the additional firing correspondence with less important inputs frequencies, which is clearly explained and visualized on the online simulation (see Supplementary Materials available here).

Process of creating synaptic plasticity is very complex; any change might be triggered in a single and short millisecond action; however the consecutive long-term results last for a long time, even days and years. STDP (the spike time dependent plasticity) is an algorithm for synaptic changes, which could be perceived as an evolution of the old Hebb principle demanding precise timing of pre- and postsynaptic spikes. According to STDP neurons need to wait for the next postsynaptic spike to decide if they prefer to turn on LTP or LTD. Recently, accuracy of such algorithm was being doubted.

In experiment carried out without stimulation the received spikes value after 10 seconds for pyramidal cells was from 229 to 321 (mean 258, SD 43.2); however in research involving LTP inducing protocol spikes value was from 262 to 348. Statistically relevant increase in spikes value in experiment with LTP inducing protocol was not observed $(\mathrm{p}=0.3123)$ (Figures 2 and 3$)$.

The solution could be the LTP related algorithm. This algorithm functions on a dendrite level, independently of each compartment in compatibility with canonical form of sc. The induced LTP protocol has a specified time of duration.

CA1 pyramidal cells LTP network (called Memory) is dependent on duration of simulation in both cases, connected with LTP induction and without it. In those simulations positive and statistically relevant correlation between time of simulation and average value Memory $\mathrm{f}$ of 4 pyramidal cells were received (Figure 5). Score without stimulation was $\mathrm{R}=0.97(\mathrm{p}=0.0001)$ and with LTP stimulation $\mathrm{R}=0.89$ $(\mathrm{p}=0.0001)$. Furthermore, in both cases statistically valid increase of pyramidal cells memory and spikes value was observed $(\mathrm{R}=0.98, \mathrm{p}=0.0001)$.

After arrival of action potential at a synapse the subsequent change of synaptic potential remains disposable for further computation. For EPSP this time of duration I pyramidal cells is $15 \mathrm{~ms}$. The amount of interspike intervals combination relies on the number of received action potentials arriving at one synapse at the same time. Making an assumption that the difference of one clock step at one interval is essential for further computing, it could be estimated that there are 6272 combinations from one spike to dense impulse of 8 spikes. If we assume that $1 \mathrm{~ms}$ is a significant distinction then we achieve 623 combinations. A total amount of variation for 16 inputs (synapses of pyramidal cells) can be calculated as 627216.

Coworkers of Kasabov presented SPAN which allows recognizing over 200 synapses' spike patterns during $200 \mathrm{~ms}$ stimulation [79]. SPAN is a spiking neuron capable of learning connections of arbitrary spike trains in a controlled fashion which enables process of spatiotemporal information encoding in the accurate timing of spikes.

\section{Discussion}

In biological neurons the precision might be less advanced due to the fact that diverse membranes current need time to raise potential. However, the mathematical models of 
Pyramidal cell 1

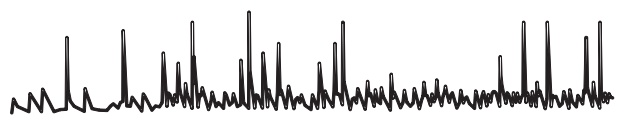

251 spikes

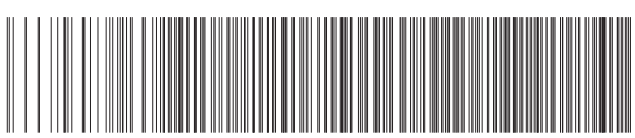

229 spikes

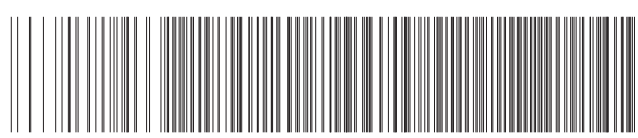

231 spikes

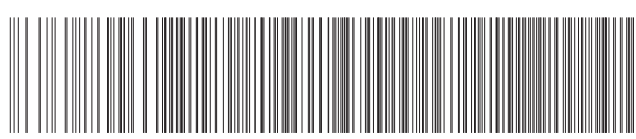

321 spikes

Pyramidal cell 4

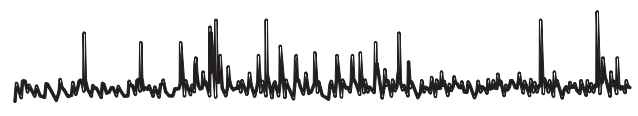

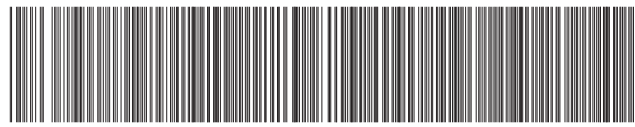

222 spikes

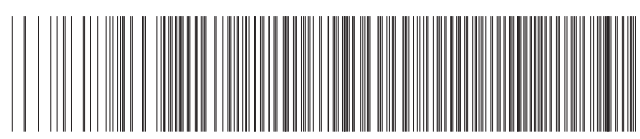

145 spikes

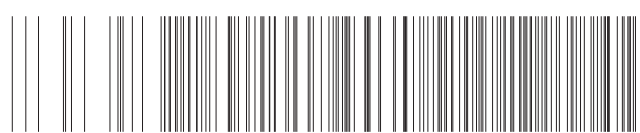

266 spikes

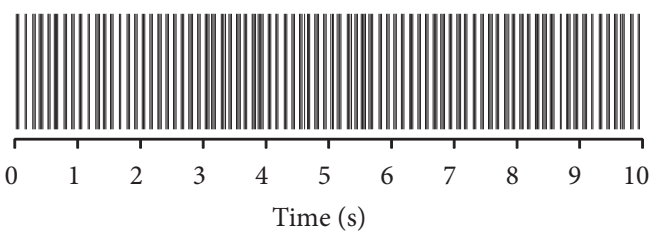

Figure 2: Basic 10-second real-time simulation of pyramidal cells, basket cells, and OL-M cell without LTP inducing protocol. On the left, time course of summarized postsynaptic potential for all cells of CA1 region. On the right, output spikes train. Time (s), forecast time of duration LTP at the end of simulation. 
Pyramidal cell 1

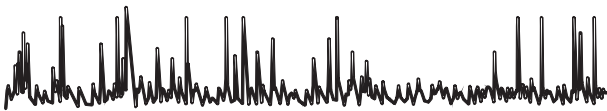

Pyramidal cell 2

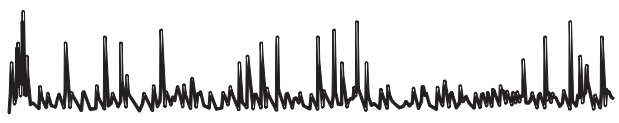

Pyramidal cell 3

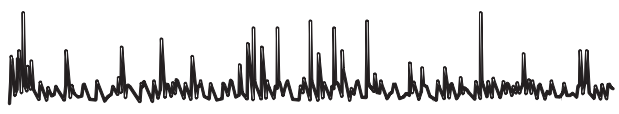

Pyramidal cell 4

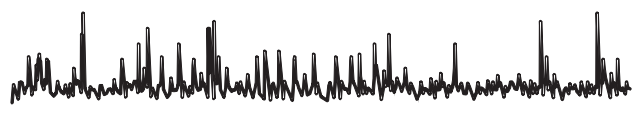

O-LM cell

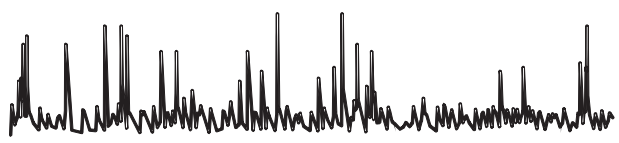

PV basket cell 1

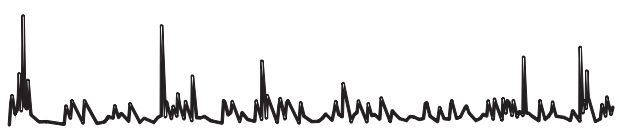

PV basket cell 2

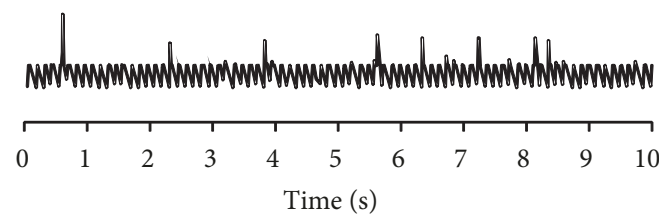

296 spikes

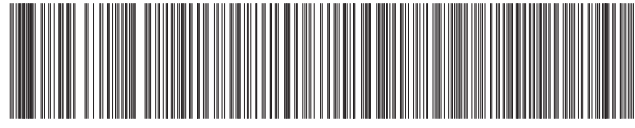

262 spikes

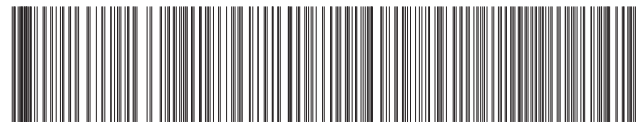

259 spikes

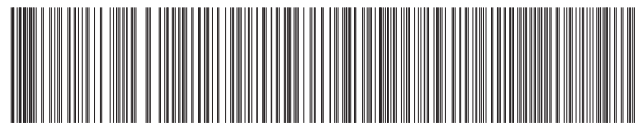

348 spikes

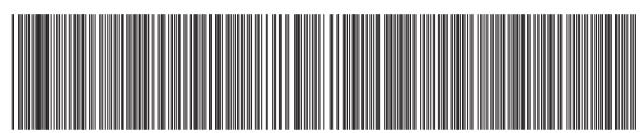

262 spikes

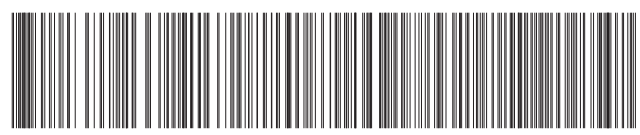

170 spikes

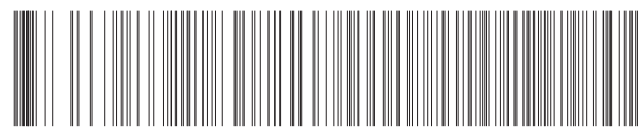

270 spikes

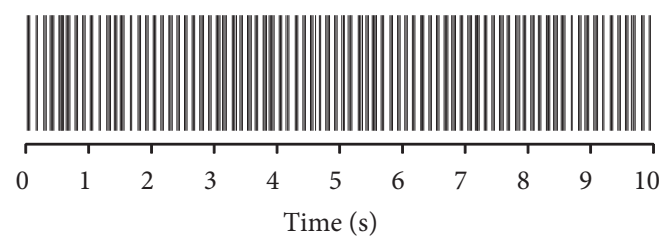

FIGURE 3: Basic 10-second real-time simulation of pyramidal cells, basket cells, and OL-M cell with LTP inducing protocol. On the left, time course of summarized postsynaptic potential for all cells of CA1 region. On the right, output spikes train. Time (s), forecast time of duration LTP at the end of simulation. 
THETA

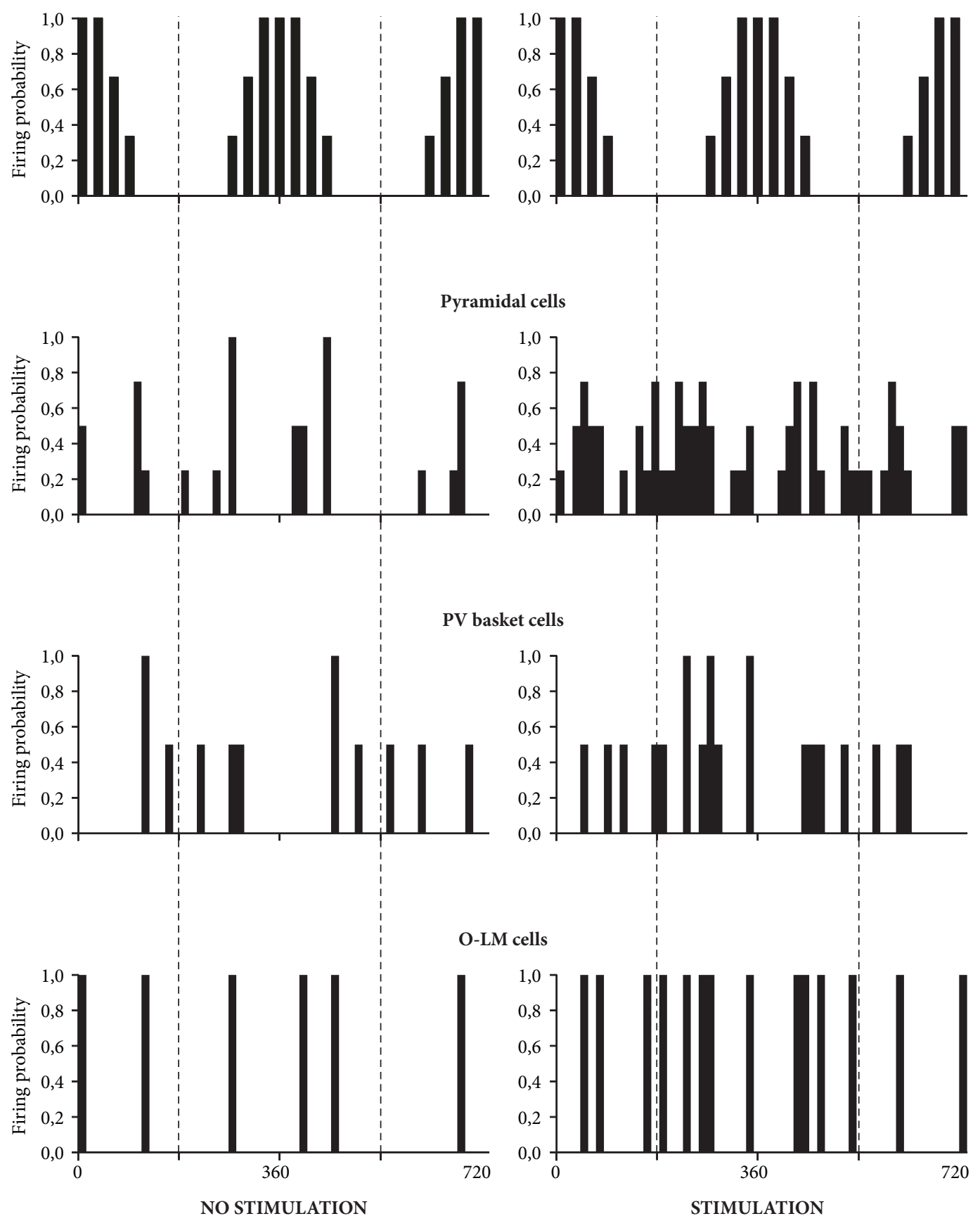

FIgURE 4: Temporal relationship between theta oscillations, pyramidal cells, basket cells, and OL-M cell. On the left, temporal relationship without LTP inducing protocol. On the right, temporal relationship with LTP inducing protocol. Histograms show the firing probability rates of all cells CA1 region.

dendrites present the capacity to perform sub-millisecond compatibility detection.

The presence of chaos process inside brain network is acknowledged and there is no possibility for precise prediction of multiple inputs data and finding any analytical solution seems to be rather impossible. The Izhikevivh model, similarly to many other models, consists of accessible differential equations with only a few parameters which appears to be easy to define [80]. Every constructed model of biological feasibility needs to be introduced with an efficient algorithm. Although there is a precise set of internal parameters for mature living neuron cells, some differences might appear in various brain areas. We have already determined the number of excitatory and inhibitory inputs with their exact location on dendrites. Then, we have estimated the parameters of postsynaptic potential, amount of time needed for threshold 

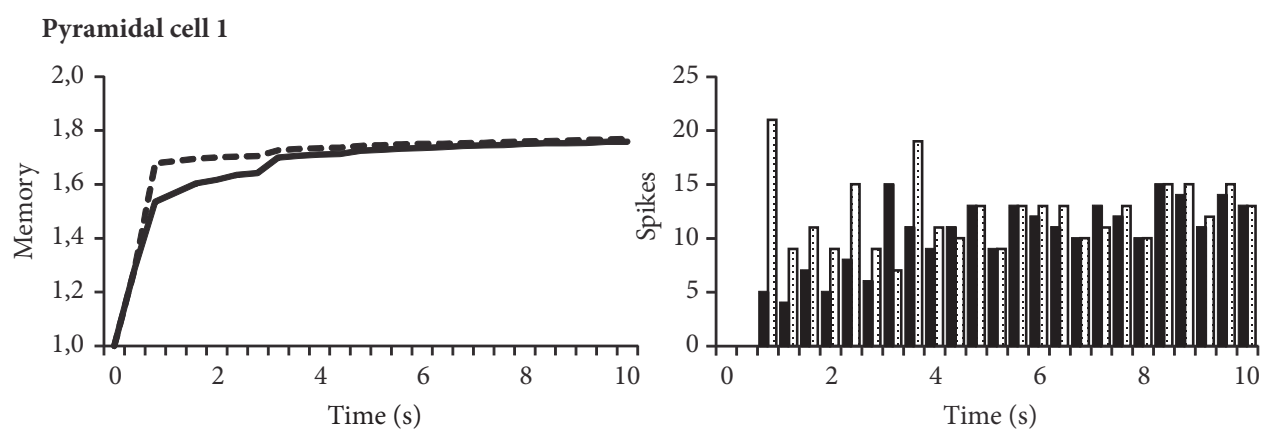

no stimulation

no stimulation

- stimulation

Pyramidal cell 2
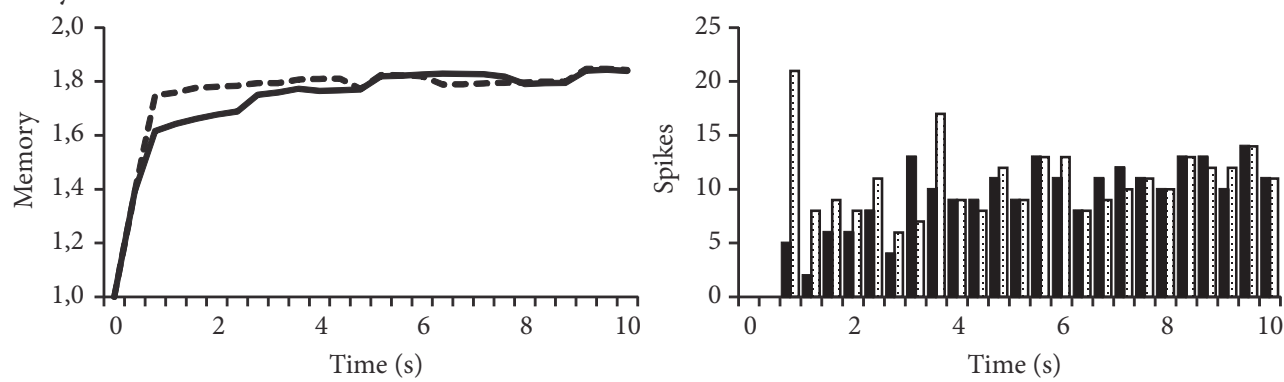

Pyramidal cell 3
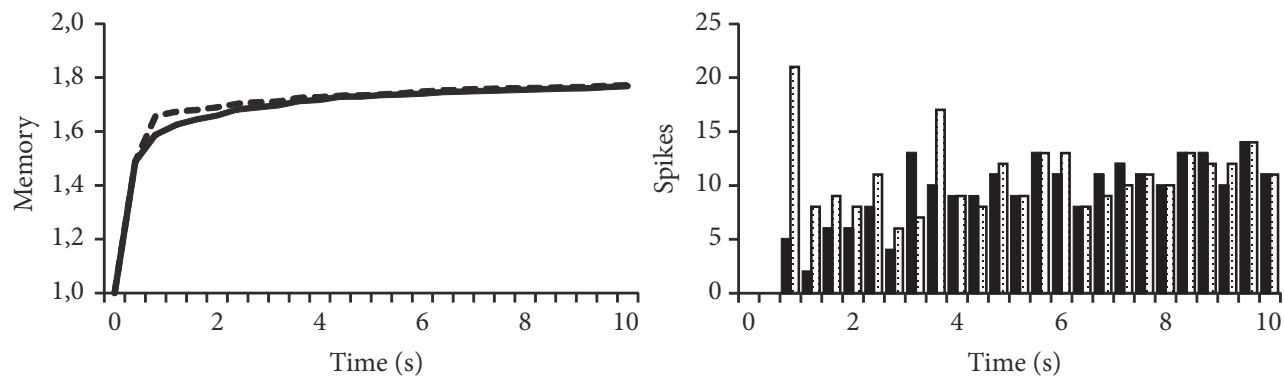

Pyramidal cell 4
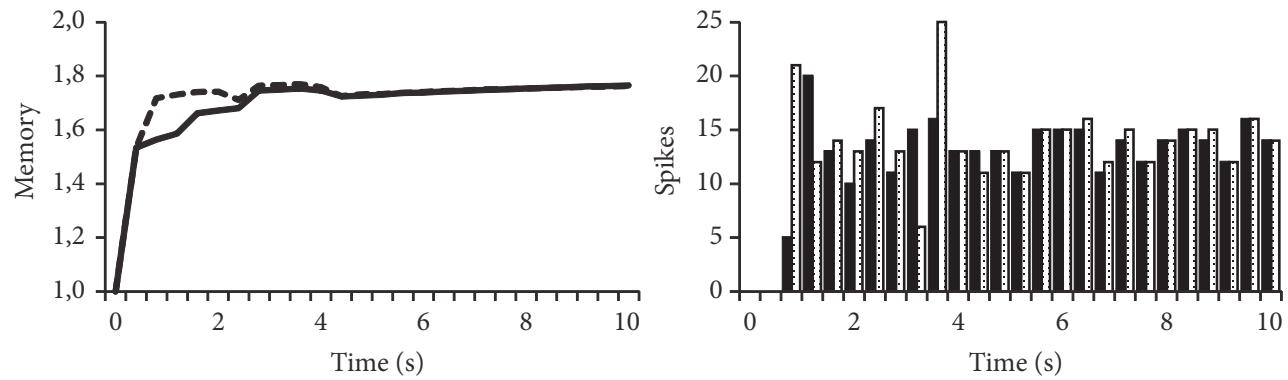

FIGURE 5: Comparison of memory during the simulation without and with LTP inducing protocol. On the left, relationship between memory function without and with LTP inducing protocol. On the right, histograms reflect number of firing spikes during 10s simulation without and with LTP inducing protocol.

and refraction, and finally two fundamental physiological values: resting potential and synaptic reversal potential. Thanks to those parameters, we have ability to present for model any algorithm weight change (learning) for the inputs (synapses). In order to inaugurate the simulation a signal for all excitatory impulses must be determined and in the Izhikevivh equation it is named as "I."

We performed more than a thousand simulations, using not only single pyramidal sells, but also a small network of ten neurons connected like in CAl hippocampal area. Any 
changes appearing in initial values or input patterns were the reason for further alterations of the interspike intervals (ISI) time series on the output. The real time of course simulations was even 10 or 20 seconds. This is the fundamental proof that the CA1 model has chaotic, dynamic characteristics.

There are some notions for the stochastic resonance phenomenon, which were firstly observed in 1950 by Bernard Langenbeck [81]. Nowadays such diagnostic methods are commonly used; however the physical white noise signal extends the capacity of inner ear receptors to react.

Undoubtedly, certain emotions such as curiosity or fear strengthen the capability to learn and memorize new models and patterns. In this process pyramidal neurons located in the cerebral cortex or hippocampus get supplementary inputs from the excited emotion areas such as amygdaloid body, which might be perceived as an indirect supervised learning algorithm. The elementary mechanism for long-term potentiation induction requires presence of NMDA channels and removal of magnesium ions blockade to enable calcium ions influx through them $[82,83]$. This is accomplished by depolarization of postsynaptic region; however instant depolarization is dependent on history of input patterns. This information may lead to a conclusion that any accessory input of all possible characteristics could potentially enlarge learning capability and should be considered as an unlike equivalent of the stochastic resonance phenomenon.

\section{Conclusions}

The most influential conclusion of all our studies seems to be the prospect of extracting pure information processing algorithm from biological backgrounds as channels and membranes. The fundamental concept of our pyramidal neuron model was derived precisely from the theory of transistors with floating gates capacitor coupling, computer language, and usual models of all biological details measured in hitherto models of neurons. We did not use any of Hodgkin-Huxley, integrate and fire, or spike timing dependent plasticity formalisms. The received outcome is a mathematical circuit which matches major apparent features of living nervous cells. Moreover, we are able to repeat the Bliss and Lomo trial for induction of long-term synaptic potentiation in the rabbit hippocampus carried out in 1973, which is presented in Figures 2 and 3 from our previous work [54].

The circuit model within shift registers working as memory buffer for any synapse is believed to have a great potential to future development of spatiotemporal computing. Such an accessible mathematical model can become a starting point for constructing biologically inspired processors which could be slightly implemented in hardware like Neuron-MOS Transistor of Shibata or Ohmi, which nowadays are arousing great interest $[84,85]$.

\section{Data Availability}

The data used to support the findings of this study are available from the corresponding author upon request.

\section{Conflicts of Interest}

The author declares that they have no conflicts of interest.

\section{Supplementary Materials}

CA1 network simulation: the video screen captures file hippocampal formation CA1 microcircuit from the simulation. On the top four pyramidal cells and on the bottom two basket cells and OL-M cell. 10-second real-time simulation of hippocampal cells with LTP inducing protocol. CA1 linear chart simulation: 10 -second real-time simulation of pyramidal cells, basket cells, and OL-M cell with LTP inducing protocol showing linear chart. On the top four pyramidal cells and on the bottom two basket cells and OL-M cell (in the middle). Linear chart shows spikes and firing hippocampal cells formation of CA1 microcircuit. (Supplementary Materials)

\section{References}

[1] G. Buzsaki, "Two-stage model of memory trace formation: a role for 'noisy' brain states," Neuroscience, vol. 31, no. 3, pp. 551570, 1989.

[2] P. Alvarez and L. R. Squire, "Memory consolidation and the medial temporal lobe: A simple network model," Proceedings of the National Acadamy of Sciences of the United States of America, vol. 91, no. 15, pp. 7041-7045, 1994.

[3] J. M. J. Murre, "TraceLink: A model of amnesia and consolidation of memory," Hippocampus, vol. 6, no. 6, pp. 675-684, 1996.

[4] S. Káli and P. Dayan, "Off-line replay maintains declarative memories in a model of hippocampal-neocortical interactions," Nature Neuroscience, vol. 7, no. 3, pp. 286-294, 2004.

[5] R. U. Muller and M. Stead, "Hippocampal place cells connected by Hebbian synapses can solve spatial problems," Hippocampus, vol. 6, no. 6, pp. 709-719, 1996.

[6] A. D. Redish and D. S. Touretzky, "The role of the hippocampus in solving the Morris water maze," Neural Computation, vol. 10, no. 1, pp. 73-111, 1998.

[7] D. J. Foster, R. G. M. Morris, and P. Dayan, "A model of hippocampally dependent navigation, using the temporal difference learning rule," Hippocampus, vol. 10, no. 1, pp. 1-16, 2000.

[8] A. Arleo and W. Gerstner, "Spatial cognition and neuromimetic navigation: a model of hippocampal place cell activity," Biological Cybernetics, vol. 83, no. 3, pp. 287-299, 2000.

[9] P. Gaussier, A. Revel, J. P. Banquet, and V. Babeau, "From view cells and place cells to cognitive map learning: Processing stages of the hippocampal system," Biological Cybernetics, vol. 86, no. 1, pp. 15-28, 2002.

[10] R. A. Koene, A. Gorchetchnikov, R. C. Cannon, and M. E. Hasselmo, "Modeling goal-directed spatial navigation in the rat based on physiological data from the hippocampal formation," Neural Networks, vol. 16, no. 5-6, pp. 577-584, 2003.

[11] M. A. Gluck and C. E. Myers, "Hippocampal mediation of stimulus representation: A computational theory," Hippocampus, vol. 3, no. 4, pp. 491-516, 1993.

[12] C. V. Buhusi and N. A. Schmajuk, "Attention, configuration, and hippocampal function," Hippocampus, vol. 6, no. 6, pp. 621-642, 1996.

[13] P. Rodriguez and W. B. Levy, "A model of hippocampal activity in trace conditioning: Where's the trace?" Behavioral Neuroscience, vol. 115, no. 6, pp. 1224-1238, 2001. 
[14] R. Granger, J. Whitson, J. Larson, and G. Lynch, "NonHebbian properties of long-term potentiation enable highcapacity encoding of temporal sequences," Proceedings of the National Acadamy of Sciences of the United States of America, vol. 91, no. 21, pp. 10104-10108, 1994.

[15] B. P. Graham, "Pattern recognition in a compartmental model of a CA1 pyramidal neuron," Network: Computation in Neural Systems, vol. 12, no. 4, pp. 473-492, 2001.

[16] M. Migliore, "On the integration of subthreshold inputs from Perforant Path and Schaffer Collaterals in hippocampal CA1 pyramidal neurons," Journal of Computational Neuroscience, vol. 14, no. 2, pp. 185-192, 2003.

[17] P. Poirazi, T. Brannon, and B. W. Mel, "Arithmetic of subthreshold synaptic summation in a model CA1 pyramidal cell," Neuron, vol. 37, no. 6, pp. 977-987, 2003.

[18] A. Lörincz and G. Buzsáki, “Two-phase computational model training long-term memories in the entorhinal-hippocampal region," Annals of the New York Academy of Sciences, vol. 911, pp. 83-111, 2000.

[19] A. Treves and E. T. Rolls, "Computational analysis of the role of the hippocampus in memory," Hippocampus, vol. 4, no. 3, pp. 374-391, 1994.

[20] J. L. McClelland and N. H. Goddard, "Considerations arising from a complementary learning systems perspective on hippocampus and neocortex," Hippocampus, vol. 6, no. 6, pp. 654665, 1996.

[21] W. B. Levy, N. L. Desmond, and D. X. Zhang, "Perforant path activation modulates the induction of long-term potentiation of the schaffer collateral-hippocampal CA1 response: Theoretical and experimental analyses," Learning \& Memory, vol. 4, no. 6, pp. 510-518, 1998.

[22] J. E. Lisman and N. A. Otmakhova, "Storage, recall, and novelty detection of sequences by the hippocampus: Elaborating on the SOCRATIC model to account for normal and aberrant effects of dopamine," Hippocampus, vol. 11, no. 5, pp. 551-568, 2001.

[23] D. Marr, "Simple memory: a theory for archicortex.," Philosophical Transactions of the Royal Society B: Biological Sciences, vol. 262, no. 841, pp. 23-81, 1971.

[24] E. Rolls, Parallel Distributed Processing, chapter Parallel distributed processing in the brain: implications of the functional architecture of neuronal networks in the hippocampus, Oxford University Press, 1989.

[25] A. Treves and E. T. Rolls, "What determines the capacity of autoassociative memories in the brain?" Network: Computation in Neural Systems, vol. 2, no. 4, pp. 371-397, 1991.

[26] A. Treves and E. T. Rolls, "Computational constraints suggest the need for two distinct input systems to the hippocampal CA3 network," Hippocampus, vol. 2, no. 2, pp. 189-199, 1992.

[27] A. Treves, "Quantitative estimate of the information relayed by the Schaffer collaterals," Journal of Computational Neuroscience, vol. 2, no. 3, pp. 259-272, 1995.

[28] B. L. McNaughton and R. G. M. Morris, "Hippocampal synaptic enhancement and information storage within a distributed memory system," Trends in Neurosciences, vol. 10, no. 10, pp. 408-415, 1987.

[29] K. Nakazawa, M. C. Quirk, R. A. Chitwood et al., "Requirement for hippocampal CA3 NMDA receptors in associative memory recall," Science, vol. 297, no. 5579, pp. 211-218, 2002.

[30] K. Nakazawa, L. D. Sun, M. C. Quirk, L. Rondi-Reig, M. A. Wilson, and S. Tonegawa, "Hippocampal CA3 NMDA receptors are crucial for memory acquisition of one-time experience," Neuron, vol. 38, no. 2, pp. 305-315, 2003.
[31] J. M. Lassalle, T. Bataille, and H. Halley, "Reversible inactivation of the hippocampal mossy fiber synapses in mice impairs spatial learning, but neither consolidation nor memory retrieval, in the Morris navigation task," Neurobiology of Learning and Memory, vol. 73, no. 3, pp. 243-257, 2000.

[32] R. C. O’Reilly and J. L. McClelland, "Hippocampal conjunctive encoding, storage, and recall: avoiding a trade-off," Hippocampus, vol. 4, no. 6, pp. 661-682, 1994.

[33] J. E. Lisman, "Relating hippocampal circuitry to function: recall of memory sequences by reciprocal dentate-CA3 interactions," Neuron, vol. 22, no. 2, pp. 233-242, 1999.

[34] N. A. Otmakhova and J. E. Lisman, "D1/D5 dopamine receptor activation increases the magnitude of early long-term potentiation at CA1 hippocampal synapses," The Journal of Neuroscience, vol. 16, no. 23, pp. 7478-7486, 1996.

[35] N. A. Otmakhova and J. E. Lisman, "Dopamine, serotonin, and noradrenaline strongly inhibit the direct perforant path-CA1 synaptic input, but have little effect on the Schaffer collateral input," Annals of the New York Academy of Sciences, vol. 911, pp. 462-464, 2000.

[36] M. E. Hasselmo and E. Schnell, "Laminar selectivity of the cholinergic suppression of synaptic transmission in rat hippocampal region CA1: Computational modeling and brain slice physiology," The Journal of Neuroscience, vol. 14, no. 6, pp. 38983914, 1994.

[37] M. E. Hasselmo and J. M. Bower, "Cholinergic suppression specific to intrinsic not afferent fiber synapses in rat piriform (olfactory) cortex," Journal of Neurophysiology, vol. 67, no. 5, pp. 1222-1229, 1992.

[38] M. E. Hasselmo, C. Bodelón, and B. P. Wyble, "A proposed function for hippocampal theta rhythm: separate phases of encoding and retrieval enhance reversal of prior learning," Neural Computation, vol. 14, no. 4, pp. 793-817, 2002.

[39] W. B. Levy, "A sequence predicting CA3 is a flexible associator that learns and uses context to solve hippocampal-like tasks," Hippocampus, vol. 6, no. 6, pp. 579-590, 1996.

[40] W. B. Levy, "A Computational Approach to Hippocampal Function," in Computational Models of Learning in Simple Neural Systems, vol. 23 of Psychology of Learning and Motivation, pp. 243-305, Elsevier, 1989.

[41] M. Nishiyama, K. Hong, K. Mikoshiba, M.-M. Poo, and K. Kato, "Calcium stores regulate the polarity and input specificity of synaptic modification," Nature, vol. 408, no. 6812, pp. 584-588, 2000.

[42] B. Widrow and M. Hoff, "Adaptive switching circuits," IRE WESCON Convention Record, vol. 4, pp. 96-104, 1960.

[43] A. Lorincz, "Forming independent components via temporal locking of reconstruction architectures: A functional model of the hippocampus," Biological Cybernetics, vol. 79, no. 3, pp. 263275, 1998.

[44] R. P. Kesner and E. T. Rolls, "A computational theory of hippocampal function, and tests of the theory: new developments," Neuroscience \& Biobehavioral Reviews, vol. 48, no. 1, pp. 92-147, 2015.

[45] H. Lehn, H.-A. Steffenach, N. M. Van Strien, D. J. Veltman, M. P. Witter, and A. K. Håberg, "A specific role of the human hippocampus in recall of temporal sequences," The Journal of Neuroscience, vol. 29, no. 11, pp. 3475-3484, 2009.

[46] E. Kropff and A. Treves, "The emergence of grid cells: Intelligent design or just adaptation?” Hippocampus, vol. 18, no. 12, pp. 1256-1269, 2008. 
[47] B. J. Kraus, M. P. Brandon, R. J. Robinson, M. A. Connerney, M. E. Hasselmo, and H. Eichenbaum, "Grid cells are time cells," Society for Neuroscience - Abstracts, pp. 769-719, 2013.

[48] B. Kraus, R. Robinson, J. White, H. Eichenbaum, and M. Hasselmo, "Hippocampal "Time Cells": Time versus Path Integration," Neuron, vol. 78, no. 6, pp. 1090-1101, 2013.

[49] E. T. Rolls, "A computational theory of episodic memory formation in the hippocampus," Behavioural Brain Research, vol. 215, no. 2, pp. 180-196, 2010.

[50] Patrick Greene, Mike Howard, Rajan Bhattacharyya, and JeanMarc Fellous, "Hippocampal Anatomy Supports the Use of Context in Object Recognition: A Computational Model," Computational Intelligence and Neuroscience, vol. 2013, Article ID 294878, 19 pages, 2013.

[51] H. Braak and E. Braak, "Neuropathological stageing of Alzheimer-related changes," Acta Neuropathologica, vol. 82, no. 4, pp. 239-259, 1991.

[52] R. A. Sandler, D. Fetterhoff, R. E. Hampson, S. A. Deadwyler, and V. Z. Marmarelis, "Cannabinoids disrupt memory encoding by functionally isolating hippocampal CA1 from CA3," PLoS Computational Biology, vol. 13, no. 7, 2017.

[53] D. Świetlik, J. Białowąs, A. Kusiak, and D. Cichońska, "Memory and forgetting processes with the firing neuron model," Folia Morphologica, vol. 77, no. 2, pp. 221-233, 2018.

[54] D. Świetlik, J. Białowąs, A. Kusiak, and D. Cichońska, "A computational simulation of long-term synaptic potentiation inducing protocol processes with model of CA3 hippocampal microcircuit," Folia Morphologica, vol. 77, no. 2, pp. 210-220, 2018.

[55] V. Cutsuridis and M. Hasselmo, "GABAergic contributions to gating, timing, and phase precession of hippocampal neuronal activity during theta oscillations," Hippocampus, vol. 22, no. 7, pp. 1597-1621, 2012.

[56] V. Cutsuridis, S. Cobb, and B. P. Graham, "Encoding and retrieval in a model of the hippocampal CA1 microcircuit," Hippocampus, vol. 20, no. 3, pp. 423-446, 2010.

[57] M. Stewart and S. E. Fox, "Do septal neurons pace the hippocampal theta rhythm?" Trends in Neurosciences, vol. 13, no. 5, pp. 163-169, 1990.

[58] G. Buzsáki, L. W. Leung, and C. H. Vanderwolf, "Cellular bases of hippocampal EEG in the behaving rat.," Brain Research, vol. 287, no. 2, pp. 139-171, 1983.

[59] A. Bragin, G. Jando, Z. Nadasdy, J. Hetke, K. Wise, and G. Buzsaki, "Gamma (40-100 Hz) oscillation in the hippocampus of the behaving rat," The Journal of Neuroscience, vol. 15, no. 1, pp. 47-60, 1995.

[60] A. Pietak and M. Levin, "Bioelectrical control of positional information in development and regeneration: A review of conceptual and computational advances," Progress in Biophysics and Molecular Biology, vol. 137, pp. 52-68, 2018.

[61] J. O’Keefe and M. L. Recce, "Phase relationship between hippocampal place units and the EEG theta rhythm," Hippocampus, vol. 3, no. 3, pp. 317-330, 1993.

[62] W. E. Skaggs, B. L. McNaughton, M. A. Wilson, and C. A. Barnes, "Theta phase precession in hippocampal neuronal populations and the compression of temporal sequences," Hippocampus, vol. 6, no. 2, pp. 149-172, 1996.

[63] Y. Omura, M. M. Carvalho, K. Inokuchi, and T. Fukai, "A lognormal recurrent network model for burst generation during hippocampal sharp waves," The Journal of Neuroscience, vol. 35, no. 43, pp. 14585-14601, 2015.
[64] G. Buzsáki, “Theta oscillations in the hippocampus," Neuron, vol. 33, no. 3, pp. 325-340, 2002.

[65] P. T. Huerta and J. E. Lisman, "Heightened synaptic plasticity of hippocampal CA1 neurons during a Cholinergically induced rhythmic state," Nature, vol. 364, no. 6439, pp. 723-725, 1993.

[66] R. P. Kesner and E. T. Rolls, "A computational theory of hippocampal function, and tests of the theory: new developments," Neuroscience \& Biobehavioral Reviews, vol. 48, no. 1, pp. 92-147, 2006.

[67] K. R. Hedrick and K. Zhang, "Megamap: Flexible representation of a large space embedded with nonspatial information by a hippocampal attractor network," Journal of Neurophysiology, vol. 116, no. 2, pp. 868-891, 2016.

[68] X.-J. Wang, "Pacemaker neurons for the theta rhythm and their synchronization in the septohippocampal reciprocal loop," Journal of Neurophysiology, vol. 87, no. 2, pp. 889-900, 2002.

[69] R. Goutagny, J. Jackson, and S. Williams, "Self-generated theta oscillations in the hippocampus," Nature Neuroscience, vol. 12, no. 12, pp. 1491-1493, 2009.

[70] C. Y. L. Huh, R. Goutagny, and S. Williams, "Glutamatergic neurons of the mouse medial septum and diagonal band of broca synaptically drive hippocampal pyramidal cells: Relevance for hippocampal theta rhythm," The Journal of Neuroscience, vol. 30, no. 47, pp. 15951-15961, 2010.

[71] J. Bialowas and M. Frotscher, "Choline acetyltransferaseimmunoreactive neurons and terminals in the rat septal complex: A combined light and electron microscopic study," Journal of Comparative Neurology, vol. 259, no. 2, pp. 298-307, 1987.

[72] M. Hajós, W. E. Hoffmann, G. Orbán, T. Kiss, and P. Érdi, “Modulation of septo-hippocampal $\theta$ activity by GABAA receptors: An experimental and computational approach," Neuroscience, vol. 126, no. 3, pp. 599-610, 2004.

[73] D. Amaral and P. Lavenex, "Hippocampal neuroanatomy," in The hippocampus book, P. Andersen, R. Morris, D. Amaral, T. Bliss, and J. O'Keefe, Eds., pp. 37-114, University Press, Oxford, UK, 2007.

[74] P. Andersen, R. Morris, D. Amaral, T. Bliss, and J. OKeefe, The hippocampus book, University Press, Oxford, UK, 2007.

[75] M. Witter, "Connectivity of the hippocampus," in Hippocampal microcircuits: A computational modeler's resource book, V. Cutsuridis, Ed., pp. 27-67, Springer, NY, USA, 2010.

[76] J. H. L. P. Sadowski, M. W. Jones, and J. R. Mellor, "Ripples make waves: Binding structured activity and plasticity in hippocampal networks," Neural Plasticity, vol. 2011, Article ID 960389, 2011.

[77] T. V. P. Bliss and G. L. Collingridge, "A synaptic model of memory: long-term potentiation in the hippocampus," Nature, vol. 361, no. 6407, pp. 31-39, 1993.

[78] T. V. P. Bliss, G. L. Collingridge, and R. G. M. Morris, "Synaptic plasticity in health and disease: Introduction and overview," Philosophical Transactions of the Royal Society B: Biological Sciences, vol. 369, no. 1633, Article ID 20130129, 2014.

[79] N. Kasabov, "To spike or not to spike: a probabilistic spiking neuron model," Neural Networks, vol. 23, no. 1, pp. 16-19, 2010.

[80] E. M. Izhikevich, "Which model to use for cortical spiking neurons?" IEEE Transactions on Neural Networks and Learning Systems, vol. 15, no. 5, pp. 1063-1070, 2004.

[81] B. Langenbeck, "Geräuschaudiometrische Diagnostik. Die Absolutauswertung," Archiv für Ohren- Nasen- und Kehlkopfheilkunde, vol. 158, no. 2-6, pp. 458-471, 1950. 
[82] M. Borjkhani, F. Bahrami, and M. Janahmadi, "Computational modeling of opioid-induced synaptic plasticity in hippocampus," PLoS ONE, vol. 13, no. 3, 2018.

[83] L. Y. Prince, T. J. Bacon, C. M. Tigaret, and J. R. Mellor, "Neuromodulation of the feedforward dentate gyrus-CA3 microcircuit," Frontiers in Synaptic Neuroscience, vol. 8, p. 32, 2016.

[84] T. Shibata and T. Ohmi, "An intelligent MOS transistor featuring gate-level weighted sum and threshold operations," in Proceedings of the International Electron Devices Meeting, IEDM 1991, pp. 919-922, USA, December 1991.

[85] T. Shibata and T. Ohmi, "Neuron MOS Binary-Logic Integrated Circuits-Part I: Design Fundamentals and Soft-HardwareLogic Circuit Implementation," IEEE Transactions on Electron Devices, vol. 40, no. 3, pp. 570-576, 1993. 


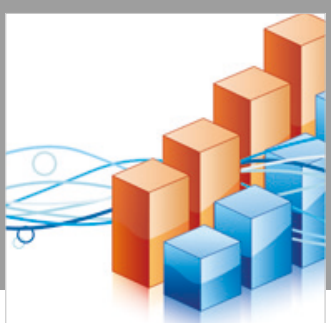

Advances in

Operations Research

\section{-n-m}
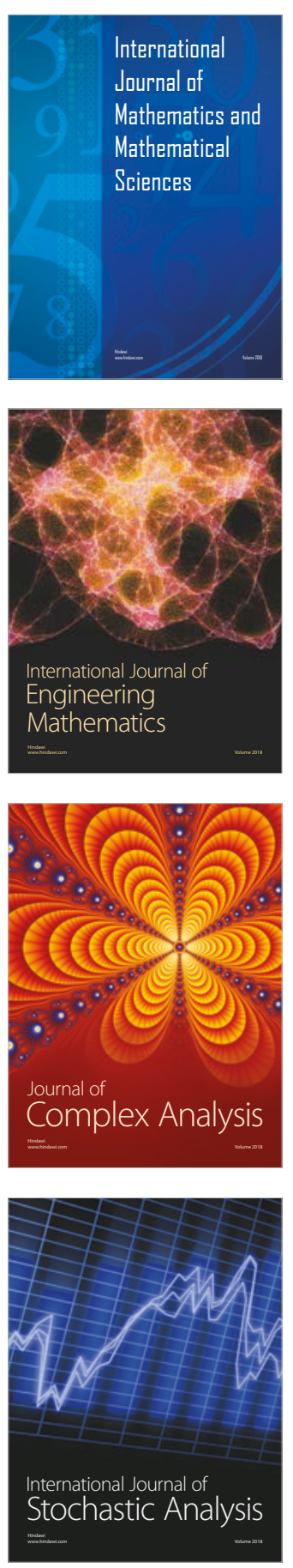
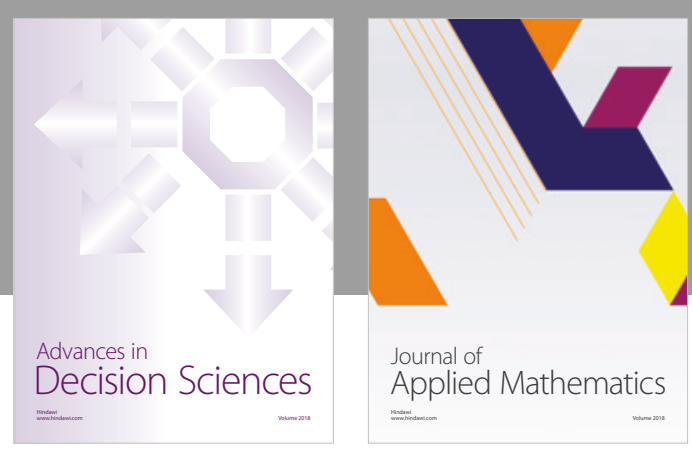

Journal of

Applied Mathematics
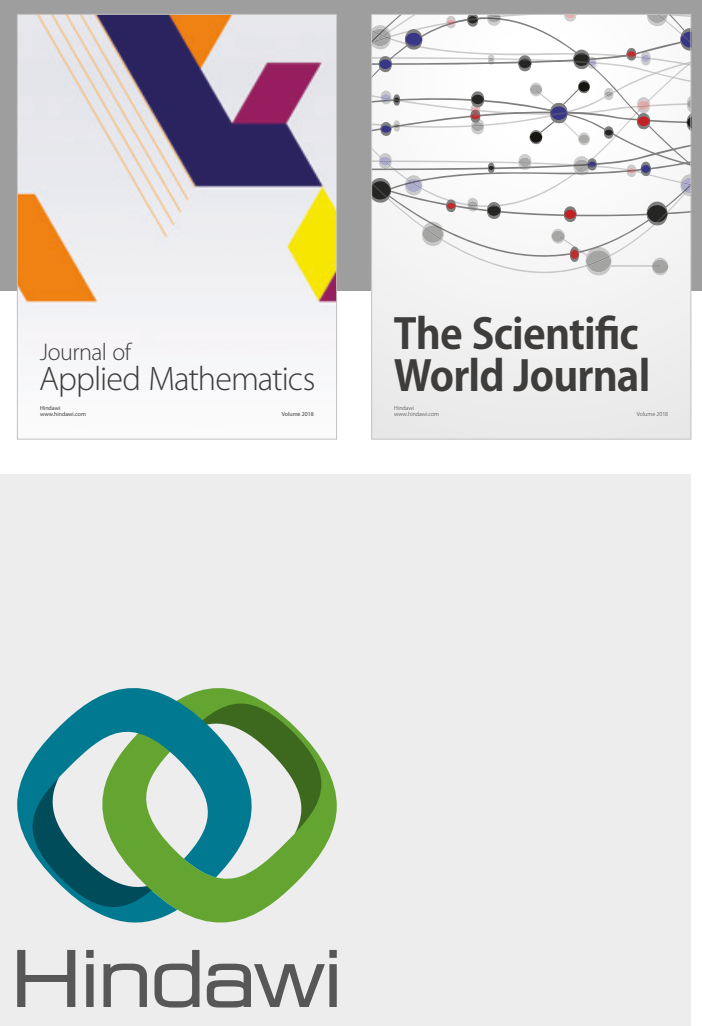

Submit your manuscripts at

www.hindawi.com

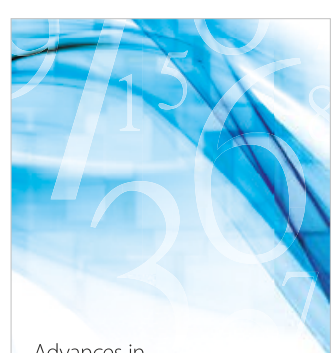

Advances in
Numerical Analysis
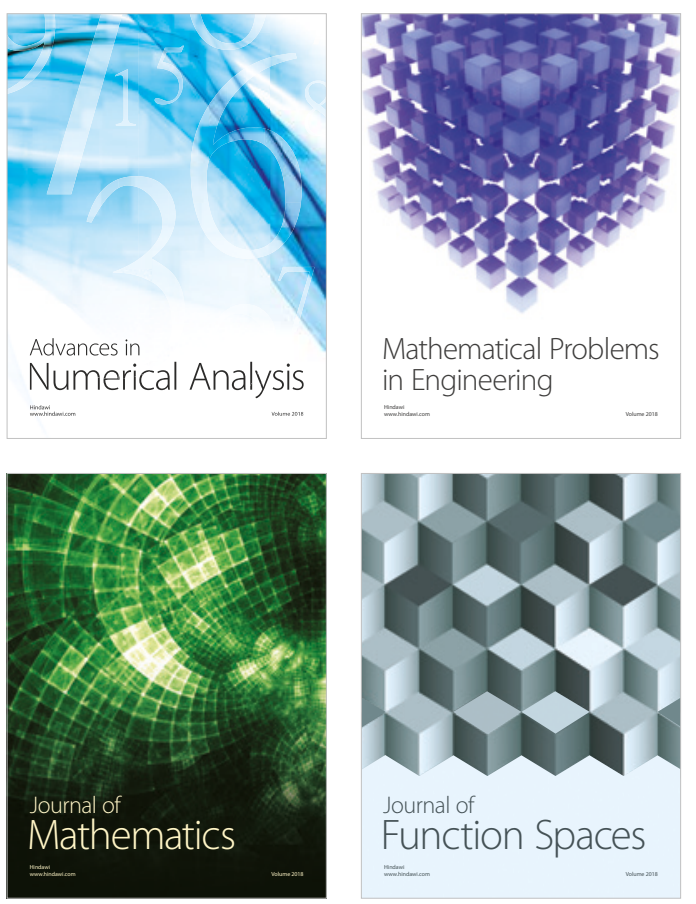

Mathematical Problems in Engineering

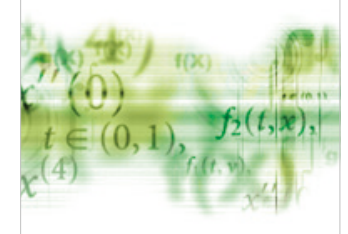

International Journal of

Differential Equations

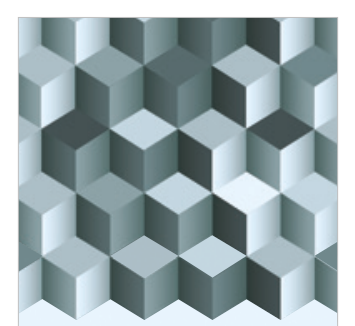

Journal of

Function Spaces
The Scientific

World Journal

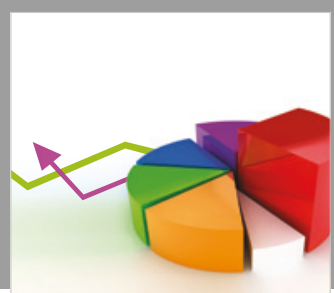

Journal of

Probability and Statistics
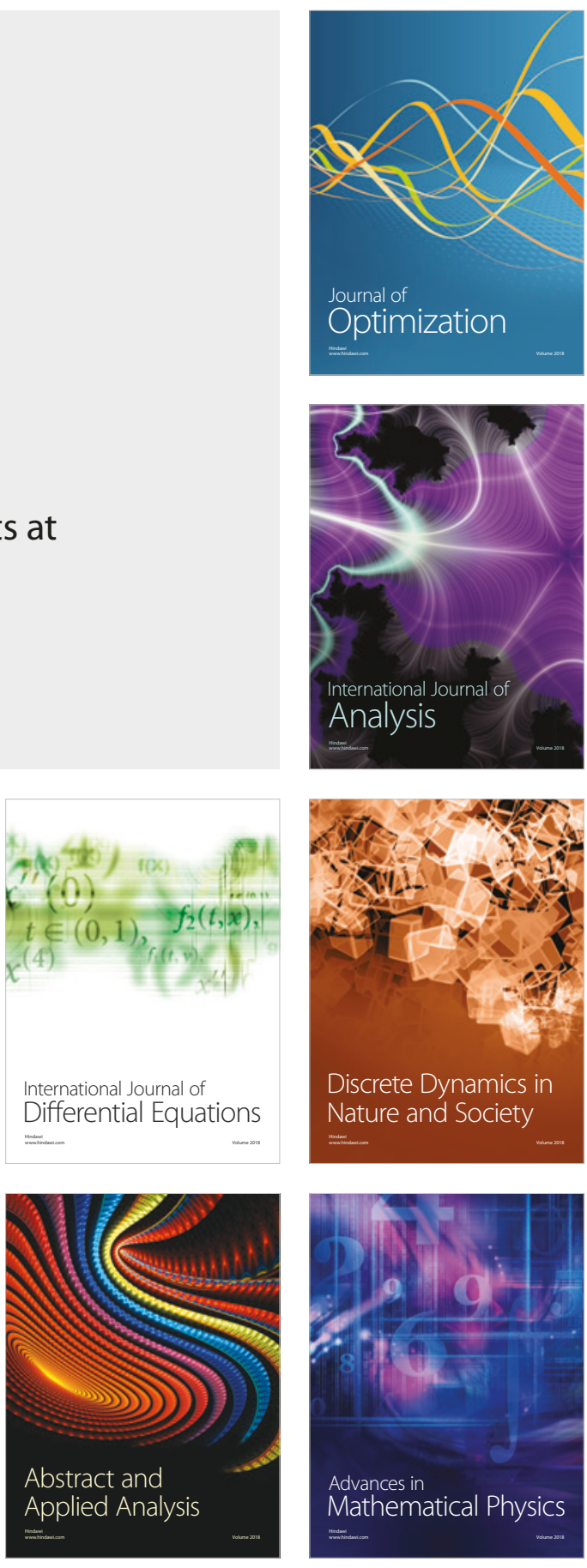